\title{
REVIEW
}

\section{Urinary Telomerase and Its Possible Role As a Marker for Bladder Cancer}

\author{
Michael J. Droller, Elizabeth Kavaler, Jaime Landman, Brian C. S. Liu \\ Department of Urology, The Mount Sinai Medical Center, New York, NY, USA
}

(Received for publication on March 27, 1998)

\begin{abstract}
Voided urine from patients with bladder cancer and from control patients with either hematuria or with no urologic conditions were examined for telomerase activity in order to explore the possibility that this activity could be used as a marker for the detection of bladder cancer. This assay was found to have an overall sensitivity in detecting bladder cancer of $85 \%(88 / 104)$ with $79 \%(23 / 29)$ grade 1 tumors, 84\% (32/38) grade 2 tumors, 87.5\% (28/32) grade 3 tumors, and 100\% (5/5) carcinoma in situ testing positive. This compared favorably with urinary cytology which had an overall sensitivity of $51 \%$ and sensitivities of $13 \%, 44 \%, 82 \%$, and $100 \%$ for grades $1,2,3$ tumors and carcinoma in situ, respectively. The specificity of telomerase in patients with benign causes of hematuria was $66 \%$, and in normal volunteers without urologic conditions, it was $100 \%$. Assessment of nuclear matrix protein suggested comparable sensitivity and specificity. Evaluation of bladder tumor antigen showed less sensitivity for low-grade disease and less specificity, as it was influenced by inflammation and instrumentation. Telomerase thus seems to be a means whereby low-grade tumors may be detected in examination of voided urine and may offer an advantage in monitoring for recurrent disease. (Keio J Med 47 (3): 135-141, September 1998)
\end{abstract}

Key words: telomerase, bladder carcinoma, urinary cytology, bladder tumor antigen

\section{Introduction}

The growing interest in the potential use of markers to detect bladder cancer has been prompted by several considerations. First, and perhaps the most important would be the possibility of having a marker so sensitive and specific that it could be used to diagnose bladder cancer with accuracy and consistency in populations at risk or with relevant signs and symptoms. Second, since bladder cancer recurs in $50-75 \%$ of the cases, a reliable marker might be used in place of cystoscopy and more effectively in place of cytology in monitoring patients for cancer recurrence. Third, development of appropriate markers based upon new information on the biologic behavior of malignancies in general and on molecular changes that determine biologic variability among various forms of bladder cancer, could potentially be used to detect and foretell recurrence or progression.
To be effective for cancer diagnosis, whether in the context of screening or surveillance, a marker should be sufficiently sensitive in detecting the cancer and sufficiently specific to avoid suggesting the diagnosis of cancer when none is present. Similarly, to be effective in predicting prognosis, a marker should indicate the likelihood of recurrence and/or progression of disease in a highly sensitive and specific manner, with sensitivity in predicting progression being at a greater premium because of the presumed value of earlier detection to permit earlier aggressive intervention.

The present report describes our experience in the application of an assay for detecting telomerase activity in voided urine as indicative of the presence of transitional cell cancer.

\section{Background}

During DNA replication, the $3^{\prime} 5^{\prime}$ (lead) strand is

Presented at the 1051st Meeting of The Keio Medical Society in Tokyo, November 8, 1997. Reprint requests to: Dr. Michael J. Droller, Department of Urology, The Mount Sinai Medical Center, One Gustave L. Levy Place, New York,
NY 10029-6574, USA 
copied in a continuous manner, whereas the $5^{\prime}-3^{\prime}$ (lag) strand is copied in a discontinuous fashion. ${ }^{1}$ As part of this discontinuous replication, so-called Okazaki fragments are coupled to segments of the single stranded DNA and are subsequently ligated by DNA repair enzymes. ${ }^{2}$ As a consequence of this process, the $3^{\prime}$ end of the lag strand may be left incompletely copied and will then be lost. Between 50 and 200 nucleotides may be lost with each replication. ${ }^{3}$

A set nucleotide sequence (TTAGGG), the so-called telomere, is located at the end of the chromosome. ${ }^{4}$ Telomeres appear to preserve the stability of the chromosome. They prevent fusion of the chromosomal ends with other chromosomes. ${ }^{5}$ They also protect the individual chromosome from endonuclease digestion. ${ }^{6}$

When all telomeres are lost during the course of multiple DNA replication, the subsequent sequential loss of parent DNA results in chromosomal instability.? This then results in apoptosis or programmed cell death. A cell can only afford to lose a finite number of telomeres, since loss of significant sequences in parent DNA will result in cell death.

Telomerase is a ribonucleoprotein that maintains the presence of telomeres at the ends of the chromosome. ${ }^{8}$ In so doing, it permits survival of cells following DNA replication, since the persistence of telomeres prevents destruction and loss of parent DNA. Activation of telomerase may therefore help transform otherwise mortal somatic cells into immortal ones. ${ }^{9}$ Thus, just as telomere length may be a marker for the replicative history of a cell, telomerase activity may be a marker for a cell's immortalization.

Most human neoplastic cells have been found to contain telomerase activity. ${ }^{10}$ How such activity is initiated, however, is unknown. Cancer cells may arise from telomerase-active stem cells that are involved in tissue remodeling. Or they may arise by reactivation of telomerase activity in normally telomerase-silent somatic cells via mutation. ${ }^{11}$

It is important to consider that activation of telomerase may not be necessary for carcinogenesis. Rather, activation of telomerase activity may be a late event in cancer development. Or, it may represent potentially more aggressive cancer diathesis since it is occasionally not found in very early cancers or in relatively benign tumor diathesis. ${ }^{11}$

Counter et al. were the first to demonstrate telomerase activity in vivo by noting extension of a $(\text { TTAGGG) })_{N}$ primer at the ends of strands of DNA. ${ }^{12}$ Kim et al. used the polymerase chain reaction and an assay called the telomerase repeat amplification protocol (TRAP) to detect telomerase activity in extracts equivalent to 100 cells from a human immortal cell line. ${ }^{13}$ Immunohistochemical staining subsequently demonstrated telomerase activity in a variety of cancers of different grades and stages. ${ }^{10,14,15}$

In urologic tumors, a reduction in telomere length was reported by Sawyer et al. in two cases of Wilm's tumors, and telomeric fusions and break points were seen in the short arm of chromosome 11, also in Wilm's tumor. ${ }^{16}$ Mehle et al. reported a decrease in the mean telomere restriction fragment length in $9 / 10$ renal cell cancers. ${ }^{17}$ The reintroduction of chromosome 3 in renal cancer cell lines was found by Ohmura et al. to produce loss of telomerase activity and restoration of cell senescence, while reintroduction of chromosome 7 or chromosome 11 did not. ${ }^{18}$ Sommerfeld et al. described telomerase activity in $21 / 25$ prostate cancer specimens, whereas adjacent cancer-negative (BPH-positive) specimens were found to have telomerase activity in only three of the 25 specimens. ${ }^{19}$ The four false negatives involved strictly organ-confined prostate cancer, while all four of the positive lymph nodes had positive telomerase activity.

\section{Studies of Telomerase in Bladder Cancer}

The assay for telomerase activity is known as the telomerase repeat amplification protocol. ${ }^{20}$ In this assay, a lysed cell specimen is incubated for 30 minutes, permitting synthesis of telomere units by any telomerase that is present. Telomeric amplification by a polymerase chain reaction then permits their detection on a polyacrylamide gel by the appearance of a ladder pattern.

In our initial studies, cell lysates were prepared from known numbers of cells from bladder cancer cell lines $\mathrm{RT}_{4}$ and $\mathrm{T}_{24} \cdot{ }^{21}$ Only $50-100$ cells were found necessary to determine the presence of telomerase activity in these specimens. As little as one cancer cell could be detected among 10,000 normal cells.

We initially studied 57 voided urine specimens from patients with bladder cancer and observed telomerase activity in 52/57 (91\%) of these. ${ }^{21}$ These comprised $13 / 13(100 \%)$ positives in patients with grade 1 tumors, $22 / 24(92 \%)$ positives in patients with grade 2 tumors, $15 / 18(83 \%)$ positives in patients with grade 3 tumors, and $2 / 2(100 \%)$ positives in patients who had only flat carcinoma in situ. Of these specimens, 41 were assessed in parallel for abnormal cytology. Only $20(49 \%)$ were interpreted as positive for malignancy. In the 21 cases which were cytologically either falsely negative or equivocal, $7 / 7(100 \%)$ negatives were in urine from patients with grade 1 tumors, $11 / 18(61 \%)$ negatives were in urine from patients with grade 2 tumors, and $3 / 14(21 \%)$ negatives were in urine from patients with grade 3 tumors. There were no cytologically false negatives in the two patients with flat carcinoma in situ. Thus, application of the telomerase assay provided a $95 \%$ detection rate for grade 1-2 tumors whereas uri- 
nary cytology provided only a $28 \%$ detection rate $(p<0.001)$. The detection rate of all cancers by the telomerase assay was $91 \%$ versus a $49 \%$ detection rate for urinary cytology $(\mathrm{p}<0.001)$.

Based upon these initial results, we examined telomerase activity in voided urine from 104 patients who had bladder cancer, 47 patients who had hematuria, and 20 individuals who had no urologic condition. ${ }^{20}$ The overall sensitivity for detection of bladder cancer in the 104 patients with documented disease was $85 \%(88 /$ 104) ${ }^{22}$ These included $23 / 29(79 \%)$ who were positive for grade 1 tumors, $32 / 38(84 \%)$ positive for grade 2 tumors, $28 / 32(87.5 \%)$ positive for grade 3 tumors, and $5 / 5(100 \%)$ positive for only flat carcinoma in situ. Among the 88 bladder cancer specimens that tested positive for telomerase, only $45(51 \%)$ tested positive for cancer by urinary cytology. These included $3 / 23$ $(13 \%)$ specimens from patients with grade 1 tumors, $14 /$ $32(44 \%)$ specimens from patients with grade 2 tumors, $23 / 28(82 \%)$ specimens from patients with grade 3 tumors, and $5 / 5(100 \%)$ specimens from patients with flat carcinoma in situ. The false-negative rate for urinary cytology was over $50 \%$, whereas the false-negative rate for telomerase was $<10 \%$. On the other hand, the false-positive rate for telomerase was $16 / 47(34 \%)$ in patients with benign causes of hematuria, whereas there were no false positives with urinary cytology. None of the voided urines from 20 normal volunteers without urologic conditions and with completely negative urinalysis had detectable telomerase activity.

Other studies that have examined telomerase activity in human urothelial tumors have presented somewhat mixed results. In one study of 22 tissue specimens from transitional cell cancers of the bladder, ureter, and renal pelvis, all of the tumors examined were telomerase positive, but high levels of activity were observed in only 5/10 stage $T_{a} / T_{1}$ tumors and $6 / 12$ stage $T_{2-4}$ tumors. ${ }^{23}$ There also appeared to be no correlation between levels of activity and tumor grade. No telomerase activity was observed in adjacent histologically normal tissue, suggesting that telomerase activity might be specific to the transformed tumor cells. In another report, telomerase activity was observed in $96 \%$ of 75 urothelial cancer tissue specimens ( 45 from superficial tumors and 30 from invasive tumors). ${ }^{24}$ No correlation was seen between negative findings and tumor stage, while eight normal tissue specimens and three specimens demonstrating dysplasia showed no telomerase activity. In 40 bladder washings from these patients, $73 \%$ showed telomerase activity. There was no correlation with tumor stage. A telomerase-positive tumor was present in nine of the telomerase-negative bladder washings. These findings suggested that early inactivation of telomerase might have occurred. Bladder washings from six patients with only dysplastic changes in the mucosa showed no telomerase activity.

In this study there was no detectable telomerase activity in the voided urines of 30 of the patients with telomerase-positive tumors. ${ }^{24}$ Since the TRAP assay detects telomerase activity and not simply the presence of the telomerase enzyme, it was suggested that living cells might need to be present for positive telomerase identification. It is also possible that various inhibitory substances such as proteases, urea, various salts, RNAases, and acidic pH may have degraded or inactivated the telomerase enzyme. Standardization of the assay protocol for general clinical application is clearly needed.

\section{Recent Studies of other Markers in Bladder Cancer}

We also examined other markers that have been proposed for use in the diagnosis of bladder cancer. Our original efforts focused on nuclear matrix protein 22 (NMP22), a protein described in recent studies as associated with the mitotic apparatus of the nuclear matrix. ${ }^{25}$ Our interest in this potential marker was based on suggestions of an association between NMP and telomerase. ${ }^{26}$ The nuclear matrix is the nuclear equivalent of the cell cytoskeleton. It is the dynamic structural subcomponent that directs the functional organization of DNA and provides specific control of nucleic acids. ${ }^{27}$ NMP is involved in DNA replication and transcription, RNA processing, and regulation of gene expression. ${ }^{28}$ Several reports have suggested that NMPs might be used to distinguish normal from neoplastic cells. ${ }^{29,30}$ NMP22, a protein component of the nuclear matrix that involves the mitotic apparatus, has been found to constitute a normal antigen in transitional epithelium that is released into the blood and urine through normal apoptosis. ${ }^{25}$ Reports that levels of NMP22 in malignant tissue were tenfold those of normal tissue ${ }^{25}$ made this a highly intriguing substance to examine for a potential role as a marker.

The assay used to detect NMP22 is a quantitative enzyme immunoassay. Because NMP22 is found in normal urothelium, its use to detect transitional cell cancer depends upon the establishment of a threshold level above which malignant cells are likely to be present and below which their presence is unlikely. In initial reports, in which NMP22 values in three sequential pooled voided urines in initial reports were less than 10 units $/ \mathrm{ml}, 86 \%$ of such patients had no evidence of malignant disease by cystoscopy. ${ }^{25}$ When NMP22 values were greater than $10 \mathrm{units} / \mathrm{ml}, 70 \%$ of these patients were found to have bladder cancer by subsequent cystoscopy. NMP22 levels were higher in patients with active transitional cell cancer (6.0 units/ $\mathrm{ml})$ or a history of transitional cell cancer $(4.1$ units $/ \mathrm{ml})$ than in healthy volunteers $(2.9$ units/ml $)$ or in patients 
with benign urologic conditions ( 3.3 units $/ \mathrm{ml}$ ). Moreover, there appeared to be no effect of intravesical chemotherapy on NMP22 levels.

Clearly, the use of a quantitative assay such as this, in contrast to an "all-or-none" phenomenon which characterizes the use of telomerase, creates a scenario in which sensitivity and specificity can be adjusted by setting a particular level as a threshold. Thus, overall sensitivity in initial reports for NMP22 was $69.7 \%$ (23/ 33 ) and specificity was $78.5 \%(62 / 79)$ when a threshold level of 10.0 units $/ \mathrm{ml}$ was used. ${ }^{25}$ The positive predictive value was $57.5 \%(23 / 40)$ and the negative predictive value was $93.1(67 / 72)$ for this threshold level. However, the sensitivity of the assay for bladder cancer decreased to $51.5 \%$ and specificity increased to $91.1 \%$ when a threshold level of 20.0 units $/ \mathrm{ml}$ was used. ${ }^{25}$ At this higher threshold, the positive predictive value was $70.8 \%$ and the negative predictive value was $81.8 \%$.

In view of the apparent relationship between NMP and telomeres at the ends of chromosomes, ${ }^{26}$ we thought it of interest to examine the same voided urines from patients with various grades of bladder cancer for both NMP22 and telomerase activity in parallel. In a series of 47 single-voided specimens, NMP22 was positive in $69 \%$ of specimens from 16 patients with grade 1 tumor, $86 \%$ of specimens from 14 patients with grade 2 tumor, $93 \%$ of specimens from 14 patients with grade 3 tumor, and $67 \%$ of specimens from three patients with only flat carcinoma in situ. ${ }^{31}$ Corresponding results with the telomerase assay in the same urine specimens were $65 \%$ in the specimens from 16 patients with grade 1 tumors, $72 \%$ in specimens from 14 patients with grade 2 tumors, $93 \%$ in specimens from 14 patients with grade 3 tumors, and $100 \%$ in specimens from three patients with flat carcinoma in situ. In the same specimens, examination of urinary cytology showed $40 \%$ sensitivity overall. Cytology was positive in $6 \%$ of the 16 patients with grade 1 tumors, $36 \%$ of the 14 patients with grade 2 tumors, $79 \%$ of the 14 patients with grade 3 tumors, and $67 \%$ of the 3 patients with flat carcinoma in situ.

In 30 patients with hematuria but without evidence of bladder cancer, the overall specificity for these assays was $77 \%$ for NMP22, $80 \%$ for telomerase, and $94 \%$ for cytology. ${ }^{31}$

A recent multiinstitutional study in patients with a prior history of transitional cell cancer examined the use of NMP22 in detecting new or recurrent lesions during routine follow-up. The difference between the median NMP22 value in the cancer-negative group (3.0 units $/ \mathrm{ml})$ and cancer-positive group $(9.8$ units $/ \mathrm{ml})$ was statistically significant $(\mathrm{p}<0.0001) .{ }^{32}$ However, the mean values in these specimens were $6.5 \mathrm{U} / \mathrm{ml}$ with a range of $0-214 \mathrm{U} / \mathrm{ml}$ and $34.6 \mathrm{U} / \mathrm{ml}$ with a range of 0 $208 \mathrm{U} / \mathrm{ml}$ respectively.

Similarly, although significant differences were observed in median NMP22 values of $T_{a} v s . T_{1}$ tumors $(7.5 \mathrm{U} / \mathrm{ml}$ and $99.0 \mathrm{U} / \mathrm{ml}$, respectively), grade $1 \mathrm{vs}$. grade 2 or grade 3 tumors $(3.02 \mathrm{U} / \mathrm{ml}, 9.41 \mathrm{U} / \mathrm{ml}$, and $39.5 \mathrm{U} /$ $\mathrm{ml}$, respectively), the range of values in each of these groups indicated substantial overlap. For example, the range in stages $T_{a}$ and $T_{1}$ tumors was $0-112 \mathrm{U} / \mathrm{ml}$ and $2.50-208 \mathrm{U} / \mathrm{ml}$, respectively. Ranges for grade 1,2 and 3 tumors were $0-112 \mathrm{U} / \mathrm{ml}, 0.7-110 \mathrm{U} / \mathrm{ml}$ and $0.5-208$ $\mathrm{U} / \mathrm{ml}$, respectively. Thus, although significant differences might exist between these groups in association with stage and grade of disease, the assay itself might not be readily applicable in an individual patient.

Construction of a receiver operating characteristics curve indicated an optimal reference value of 6.4 units/ $\mathrm{ml}$, which provided $68 \%$ sensitivity and $80 \%$ specificity for the detection of transitional cell cancer (with a positive predictive value of $51.7 \%$ and a negative predictive value of $88.8 \%$ ). If a threshold of $10 \mathrm{U} / \mathrm{ml}$ was used, sensitivity decreased to $48.5 \%$, while specificity increased to $91.4 \%$ (with a positive predictive value of $65.3 \%$ and a negative predictive value of $84.9 \%$ ).

In this study, the overall sensitivity for NMP22 of $67 \%$ compared favorably with that of urinary cytology $(31 \%)$. Differences in stage $T_{a}$ for NMP22 $(54 \%)$ versus cytology $(14 \%)$ were even more impressive. However, the sensitivity of NMP22 for detecting carcinoma in situ was only $70 \%$, whereas it was $100 \%$ with urinary cytology. Thus, NMP22 appears to offer advantages over urinary cytology largely in terms of an increased detection rate for low-grade disease. However, there were also disadvantages in its decreased specificity possibly influenced by inflammation, occult disease or other malignancy, and a positive predictive value. Moreover, the large differences between mean and median values and the broad range of the different test values leaves concern as to whether this test will ultimately be found to be clinically practical in the individual patient.

We also examined the same voided urine specimens for bladder tumor antigen (BTA), a substance released into the urine from the urothelial basement membrane, presumably as the result of the lytic activity of the malignant cells on the extracellular matrix material. ${ }^{33}$ Previous studies have reported sensitivities of BTA of $30-50 \%$ for grade 1 tumors, $40-60 \%$ for grade 2 tumors, and $50-70 \%$ for grade 3 tumors. ${ }^{33,34}$ Specificity of the BTA assay has been reported to range from 80 $90 \%$ but has been found to vary with inflammation, prior instrumentation, and infection, in which sensitivity

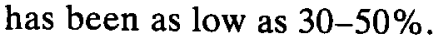

In our own investigations of BTA activity in voided urine specimens, overall sensitivity was found to be only $40 \%$. In the 47 voided urine specimens described above, the BTA test was positive in only $13 \%$ of 16 specimens from patients with grade 1 disease, $36 \%$ of 14 specimens from patients with grade 2 disease, and 
$79 \%$ in 14 specimens from patients with grade 3 disease. It was positive in only one of the three patients with flat carcinoma in situ alone. Its overall specificitiy was $70 \%$. Thus, the BTA test did not appear to compare favorably with either telomerase or NMP22 in detecting low-grade or low-stage disease. In addition, its elevation in the setting of inflammation, instrumentation, and other noncancer situation appeared to compromise its clinical utility.

Recent reports have described the introduction of two new "BTA" tests, the "BTA stat" test, and the "BTA trak" test. ${ }^{35.36}$ The BTA stat test is an immunochromatographic assay for the detection of a so-called bladder tumor-associated antigen that has been identified as a human complement factor $\mathrm{H}$-related protein, similar in composition, structure, and function to human complement factor $\mathrm{H}^{37}$ This protein has been found to be produced by several human bladder cancer cell lines, but not by other epithelial cell lines, and is thought to play an inhibitory role in the control of the alternative complement pathway that functions to lyse cells that are recognized as foreign by the host. The BTA trak assay is an enzyme immunoassay that detects the same protein but may offer the advantage of quantification which could assist in assessing response to therapy or disease progression. ${ }^{36}$

In the BTA stat test, an overall sensitivity of $67 \%$ was obtained in voided urine samples from 220 patients with histologically confirmed bladder cancer. This could be stratified by grade $(42 \%, 66 \%$, and $83 \%$ sensitivity for grades 1,2 , and 3 tumors, respectively) and by stage $\left(51 \%, 89 \%, 88 \%\right.$, and $61 \%$ sensitivity for stages $T_{a}, T_{1}$, $\mathrm{T}_{2-4}$, and carcinoma in situ, respectively). ${ }^{35}$ Specificity in healthy volunteers was $95 \%$, but decreased to $50 \%$ in patients with stones, $76 \%$ in patients with inflammatory or infectious conditions such as cystitis, urethritis, and prostatitis, and $33 \%$ with invasive manipulation of the urinary tract. Of interest were observations that 9 of 32 "false-positives" among 107 patients who were being monitored for recurrent cancer developed documented cancer recurrence within one year. ${ }^{35}$ The sensitivity of the BTA stat test was reported to be significantly superior to cytology for each histologic grade of tumor and for stages $T_{a}$ and $T_{1}$. It was felt to be equivalent to cytology for carcinoma in situ. However, the sensitivity of urinary cytology in this investigation was only $8 \%$, $18 \%$, and $38 \%$ for grades 1,2 , and 3 disease, respectively, and only $60 \%$ for carcinoma in situ. These observations are inconsistent with results in other reports by other authors who have commented on the role of urinary cytology in diagnosing low-grade cancers (sensitivity was substantially higher than in the present report) while confirming the value of this modality for high-grade cancers and carcinoma in situ. ${ }^{38}$

Examination of the same urine samples with the
BTA trak assay demonstrated a sensitivity of $72 \%$ with mean values increasing as grade and stage increased (212 $\mathrm{U} / \mathrm{ml}$ in grade 1 disease, $543 \mathrm{U} / \mathrm{ml}$ in grade 2 disease, and $914 \mathrm{U} / \mathrm{ml}$ in grade 3 disease; corresponding levels by stage were $316 \mathrm{U} / \mathrm{ml}$ for stage $T_{a}$ disease, 851 $\mathrm{U} / \mathrm{ml}$ for stage $T_{1}$ disease, $1250 \mathrm{U} / \mathrm{ml}$ for stage $T_{2-4}$, and $68 \mathrm{U} / \mathrm{ml}$ for flat carcinoma in situ). However, the range for each of these was great with substantial overlap. Moreover, renal disease, urinary infection, prostate cancer, renal cell cancer, and instrumentation each increased the levels. Thus, when a threshold level of 14 units $/ \mathrm{ml}$ was used, $15 \%$ of men with benign enlargement of the prostate, $41 \%$ of patients with renal diseases, $43 \%$ of patients with inflammatory conditions or urinary infections, $31 \%$ of men with prostate cancer, $57 \%$ of patients with renal cell cancer, and $78 \%$ of patients with recent instrumentation showed elevations.

The issues involved in the clinical application of these tests concern their low sensitivity and findings that other conditions may produce positive tests. Therefore, they may not be reliable in detecting low-grade cancer, may be less accurate than cytology in detecting highgrade disease, and may produce misleading information suggesting that tumors may be present when they may not truly be.

An additional issue involves the manner in which a quantitative test (such as the BTA trak test and the NMP22 test) should be used in evaluating results on the basis of their relation to a threshold level. Some have proposed that the relationship between a quantitative diagnostic marker level and the presence of disease can be estimated by using a proportional hazard regression model. ${ }^{39,40}$ In this, the hazard ratio estimates the relationship between a particular threshold that is considered diagnostic and the possibility that a situation is actually diagnosed. This represents the extent to which that particular level may influence the hazard of the event occurring. The standard means of determining the value of a tumor marker is to estimate the sensitivity in patients who have been diagnosed as having had the condition and the specificity in patients who have not had such a diagnosis made. In both cases, a threshold level is determined for the particular marker being evaluated. However, in a quantitative assay, a high level of the marker may be indicative of disease before the disease is detectable by standard methods that may be less sensitive. This may create a bias against the marker.

In the use of a quantitative marker, there may be substantial overlap in the distribution of the measurements that are made. This could influence the possibility of identifying a clinically useful cut-off level for a particular marker. Therefore, though a quantitative marker may have potential use as a guide either for the frequency of diagnostic assessments of the status of a 
particular condition or for the application of treatment strategies, it may be of less value than a qualitative "allor-none" marker in diagnosis in an individual patient.

\section{Discussion}

The usefulness of any tumor marker depends not only upon its sensitivity and specificity but the questions that the marker is meant to answer and the population to which it is applied. Thus, for a marker to be useful for screening requires not only that the marker be highly sensitive and specific but also that the disease it detects be sufficiently commonplace so that the test's application in the general population is of diagnostic value and is cost-effective. A marker may be clinically more valuable and economically more useful when applied to either a population at risk or a population in which the presence of the disease has been identified and treated but surveillance for recurrence is required.

In bladder cancer, populations of patients who have a history of cigarette smoking or environmental exposure to known bladder carcinogens $\mathrm{s}^{41,42}$ may constitute the group most likely to benefit from the application of a test that has high sensitivity, since this may detect the presence of bladder cancer early in its development in populations which are at significant risk. However, unless the specificity is also high, such patients could be forced to undergo repetitive evaluation unnecessarily because the test was found to be positive when disease was not present. Similar considerations could be applied in the surveillance of patients with a previous history of bladder cancer. In these, a noninvasive cost-effective test could be used to advantage if it had sufficiently high sensitivity to detect the recurrence of disease early when volume of disease was less or before progression had taken place. Specificity should also be high in these instances. Otherwise, an unproductive search for nonexistent recurrent disease may be undertaken.

Each of these considerations should be placed in the context of the means by which bladder cancer is diagnosed. The assessment of the sensitivity of potential markers for bladder cancer has generally been based upon cystoscopic or cytologic diagnosis. However, a marker could conceivably be more sensitive than standard diagnostic methods. Thus, the true sensitivity of substances currently being studied for their potential clinical applicability may not have been fully characterized. Moreover, in those instances in which the threshold level of a particular substance is being used to evaluate its relationship to the presence of disease, assessment of sensitivity on the basis of that threshold also needs to take into account the range of values measured and the way in which this may affect the practical clinical application of the assay. ${ }^{39}$ A quantitative assay may need to be analyzed on the basis of a hazard proportion for the presence of disease that a certain threshold level may indicate. ${ }^{40}$ The resultant hazard ratio may conceivably be used to determine how aggressive further testing or treatment needs to be.

According to these problems taken together, there are currently no tests that are completely reliable for use in screening and none that have been sufficiently validated for the detection of bladder cancer in populations at risk. Such validation would be required both in assessing the practical use of particular substances as markers and in ascertaining their positive and negative predictive values for general use. The increasing interest in establishing molecular profiles for tumors and predicting the potential biologic activity of particular bladder cancers has increased interest in the potential use of such markers. The next few years may witness their validation and appropriate application to identifiable populations at risk.

\section{Reference}

1. Dignam JD, Lebovitz RM, Roeder RG: Accurate transcription initiation by RNA polymerase II in a soluble extract from isolated mammlian nuclei. Nucleic Acids Res 1983; 11: 1475-1489

2. Olovinikov AM: A theory of marginotomy. The incomplete copying of template margin in enzyme synthesis of polynucleotides and biological significance of the phenomenon. $J$ Theor Biol 1973; 41: 181-190

3. Blackburn EH: Structure and function of telomeres. Nature 1991; 350: 569-573

4. Blackburn EH: Telomeres: no end in sight. Cell 1994; 77: 621623

5. Moyzis RK, Buckingham JM, Cram LS, Dani M, Deaven LL, Jones MD, Meyne J, Ratliff RL, Wu JR: A highly conserved repetitive DNA sequence, (TTAGGG)n, present at the telomeres of human chromosomes. Proc Natl Acad Sci US A 1988; 85: $6622-6626$

6. Holt SE, Shay JW, Wright WE: Refining the telomere-telomerase hypothesis of aging and cancer. Nature Biotechnol 1996; 14: 836-839

7. Harley CB: Telomere loss: mitotic clock or genetic time bomb? Mutat Res 1991; 256: 271-282

8. Rhyu MS: Telomeres, telomerase, and immortality. J Natl Cancer Inst 1995; 87: 884-894

9. Haber DA: Telomeres, cancer, and immortality. N Engl J Med 1995; 332: 955-956

10. Kyo $S$, Kanaya $T$, Ishikawa $H$, Ueno $H$, Inoue $M$ : Telomerase activity in gynecological tumors. Clin Cancer Res 1996; 2: 20232028

11. Shay JW, Wright WE: The reactivation of telomerase activity in cancer progression. Trends Genet 1996; 12: 129-131

12. Counter CM, Avilion AA, LeFeuvre CV, Stewart NG, Greider $\mathrm{CW}$, Harley CB, Bacchetti S: Telomere shortening associated with chromosome instability is arrested in immortal cells which express telomerase activity. EMBO J 1992; 11: 1921-1929

13. Kim NW, Piatyszek MA, Prowse KR, Harley CB, West MD, Ho PL, Coviello GM, Wright WE, Weinrich SL, Shay JW: Specific association of human telomerase activity with immortal cells and cancer. Science 1994; 266: 2011-2015

14. Hiyama K, Hiyama E, Ishioka S, Yamakido M, Inai K, Gazdar AF, Piatyszek MA, Shay JW: Telomerase activity in small-cell 
and non-small-cell lung cancers. J Natl Cancer Inst 1995; 87: 895-902

15. Chadeneau C, Hay K, Hirte HW, Gallinger S, Bacchetti S: Telomerase activity associated with acquisition of malignancy in human colorectal cancer. Cancer Res 1995; 55: 2533-2536

16. Sawyer JR, Goosen LS, Stine C, Thomas JR: Telomere fusion as a mechanism for the progressive loss of the short arm of chromosome 11 in an anaplastic Wilms' tumor. Cancer 1994; 74: 767 773

17. Mehle C, Ljungberg B, Roos G: Telomere shortening in renal cell carcinoma. Cancer Res 1994; 54: 236-241

18. Ohmura H, Tahara H, Suzuki M, Ide T, Shimizu M, Yoshida MA, Tahara E, Shay JW, Barrett JC, Oshimura M: Restoration of the cellular senescence program and repression of telomerase by human chromosome 3. Jpn J Cancer Res 1995; 86: 899-904

19. Sommerfeld HJ, Meeker AK, Piatyszek MA, Bova GS, Shay JW, Coffey DS: Telomerase activity: a prevalent marker of malignant prostate tissue. Cancer Res 1996; 56: 218-222

20. Wright WE, Shay JW, Piatyszek MA: Modifications of a telomeric repeat amplification protocol (TRAP) result in increased reliability, linearity and sensitivity. Nucleic Acids Res 1995; 23: 3794-3795

21. Kavaler E, Shu WP, Chang Y, Droller MJ, Liu BCS: Detection of human bladder cancer cells in voided urine samples by assaying for the presence of telomerase activity. J Urol 1997; 157 (Suppl): 338

22. Kavaler E, Landman J, Chang Y, Droller MJ, Liu BC: Detecting human bladder carcinoma cells in voided urine samples by assaying for the presence of telomerase activity. Cancer 1998; 82: 708-714

23. Kyo S, Kunimi K, Uchibayashi T, Namiki M, Inoue M: Telomerase activity in human urothelial tumors. Am J Clin Pathol 1997; 107: 555-560

24. Müller M, Heine B, Heicapell R, Emrich T, Hummel M, Stein H, Miller K: Telomerase activity in bladder cancer, bladder washings and in urine. Int J Oncol 1996; 9: 1169-1173

25. Soloway MS, Briggman V, Carpinito GA, Chodak GW, Church PA, Lamm DL, Lange P, Messing E, Pasciak RM, Reservitz GB, Rukstalis DB, Sarosdy MF, Stadler WM, Thiel RP, Hayden CL: Use of a new tumor marker, urinary NMP22, in the detection of occult or rapidly recurring transitional cell carcinoma of the urinary tract following surgical treatment. J Urol 1996; 156: 363-367

26. De Lange $\mathrm{T}$ : Human telomeres are attached to the nuclear matrix. EMBO J 1992; 11: 717-724

27. Berezney R: The nuclear matrix: a heuristic model for investigating genomic organization and function in the cell nucleus. $J$ Cell Biochem 1991; 47: 109-123

28. Berezney $R$, Coffey DS: Identification of a nuclear protein matrix. Biochem Biophys Res Commun 1974; 60: 1410-1417

29. Bidwell JP, Fey EG, van Wijnen AJ, Penman S, Stin JL, Lian JB,
Stein GS: Nuclear matrix proteins distinguish normal diploid osteoblasts from osteosarcoma cells. Cancer Res 1994; 54: 28-32

30. Keesee SK, Briggman JV, Thill G, Wu YJ: Utilization of nuclear matrix proteins for cancer diagnosis. Crit Rev Eukaryot Gene Expr 1996; 6: 189-214

31. Landman J, Chang Y, Kavaler B, Droller MJ, Liu B C-S.: Sensitivity and specificity of NMP-22, telomerase, and BTA in the detection of human bladder cancer. Urology 1998; 52: 398-402

32. Stampfer DS, Carpinito GA, Rodriguez-Villaneuva J, Willsey LW, Dinney CP, Grossman HB, Fritsche HA, McDougal WS: Evaluation of NMP22 in the detection of transitional cell carcinoma of the bladder. J Urol 1998; 159: 394-398

33. Sarosdy MF, deVere White RW, Soloway MS, Sheinfeld J, Hudson MA, Schellhammer PF, Jarowenko MV, Adams G, Blumenstein BA: Results of a multicenter trial using the BTA test to monitor for and diagnose recurrent bladder cancer. $J$ Urol 1995; 154: 379-383

34. Leyh W, Mazeman E, Hall RR, Bennett AH: Results of a European multicenter trial comparing the Bard BTA test to urine cytology in patients suspected of having bladder cancer. $J$ Urol 1996; 155(Suppl): 492A

35. Sarosdy MF, Hudson MA, Ellis WJ, Soloway MS, deVere White R, Sheinfeld J, Jarowenko MV, Schellhammer PF, Schervish EW, Patel JV, Chodak GW, Lamm DL, Johnson RD, Henderson M, Adams G, Blumenstein BA, Thoelke KR, Pfalzgraf RD, Murchison HA, Brunelle SL: Improved detection of recurrent bladder cancer using the Bard BTA stat Test. Urology 1997; 50: 349-353

36. Ellis WJ, Blumenstein BA, Ishak LM, Enfield DL: Clinical evaluation of the BTA TRAK assay and comparison of voided urine cytology and the Bard BTA test in partients with recurrent bladder tumors. Urology 1997; 50: 882-887

37. Kinders R, Jones T, Root R, Murchison H, Bruce C, Williams L, Hass GM: Human bladder tumor antigen is a member of the RCA (regulators of complement activation) gene family. J Urol 1997; 157(Suppl): 28

38. Murphy WM, Crabtree WN, Jukkola AF, Soloway MS: The diagnostic value of urine versus bladder washing in patients with bladder cancer. J Urol 1981; 126: 320-322

39. Blumenstein B. Personal communication.

40. Gail MH: Evaluating serial cancer marker studies in patients at risk of recurrent disease. Biometrics 1981; 37: 67-78

41. Morrison AS, Buring JE, Verhoeck WG, Aoki K, Leck I, Ohno $\mathrm{Y}$, Obata $\mathrm{K}$ : An international study of smoking and bladder cancer. J Urol 1984; 131: 650-654

42. Case RA, Hosker ME, McDonald DB, Pearson JT: Tumours of the urinary bladder in workmen engaged in the manufacture and use of certain dyestuff intermediates in the British chemical industry. Part I. The role of aniline, benzidine, alpha-naphthylamine, and beta-naphthylamine. Br J Ind Med 1954; 11: 75-104 